\title{
Dietary Effect of Capric Acid Containing Soyphospholipids
}

\author{
Sayantani Dasgupta ${ }^{1}$ and Dipak Kumar Bhattacharyya ${ }^{2 *}$ \\ ${ }^{1}$ Berhampore Girls' College (Berhampore, Murshidabad, West Bengal, INDIA) \\ ${ }^{2}$ Department of Chemical Technology, University of Calcutta, University Colleges of Science \& Technology (92, A.P.C. Road, Kolkata \\ 700009, INDIA)
}

\begin{abstract}
A comparative evaluation of the dietary effect between capric acid (C10:0)- containing soyphospholipids and soyphospholipids without capric acid on the lipid profile of serum of rats when ingested at $5 \%$ or $10 \%$ level by weight in soybean oil was made. Rats were taken in five groups. One group was fed $20 \%$ soybean oil. Two groups received soybean oil containing $5 \%$ and $10 \%$ soyphospholipids by weight, respectively. Other two groups were fed soybean oil containing $5 \%$ and $10 \%$ capric acid containing soyphospholipids by weight, respectively. The other dietary components remained same for all the groups. The feeding was done for 4 weeks. At the end of feeding period there was no althrough significant change in weight gain, food intake and food efficiency ratio (FER). No significant change was observed in serum lipid profiles between the rats fed soybean oil and soybean oil with $5 \%$ or $10 \%$ soyphospholipids. There was significant decrease in serum total cholesterol (TC) and high density lipoprotein (HDL)-cholesterol level in the rats fed soybean oil blended with capric acid containing soyphospholipids at $5 \%$ level. The level of TC, triglyceride (TG), very low density lipoprotein (VLDL)-cholesterol decreased significantly when the rats were fed capric acid containing soyphospholipids at $10 \%$ level. There is overall significant change in TC, TG, VLDL- and LDL-cholesterol. The possible mechanism behind the reduction of serum lipid profile may be the reduction of interfacial tension of phospholipids could affect serum lipid profiles due to enhanced or much greater extent of emulsification of the both polar and nonpolar lipid components and their transfer from the intestine to the bile pathway.
\end{abstract}

Key words: capric acid, soyphospholipids, soybean oil

\section{INTRODUCTION}

In recent years, considerable interest is growing in altering the existing fatty acid profile of phospholipids just to extend their scope of applications. Soyphospholipids are receiving interest for modification by chemical or enzymatic process. Soyphospholipids thus modified could have better surface active properties and nutritional quality than the original compounds. Still there is not so extensive research on the modification of phospholipids and also on their nutritional value.

Phospholipids are recognized surface active molecules and are of lower calorie compared to the triacylglycerols having fatty acids of equivalent chain length. Medium chain triacylglycerols have also lower calorie content almost close to that of phospholipids. Both these molecules are known to reduce cholesterol including LDL-cholesterol. Phospholipids are also believed to be hypocholesterolemic agents ${ }^{1,2}$. Lecithin decreases LDL-cholesterol and increases HDL-cholesterol in serum ${ }^{3)}$ and may also suppress intestinal cholesterol absorption ${ }^{4}$. A recent study indicates that the interfacial tension of soyphospholipids gets reduced when a medium chain saturated fatty acid is incorporated in it ${ }^{5}$. Capric acid is a medium chain fatty acid and because of its saturation, it is stable to oxidation. It has small molecular size and relatively much greater affinity to aqueous phase which contribute to different digestive and absorptive properties compared to long chain triglycerides (LCT) and original soyphospholipids. Medium chain triglycerides (MCT) are rapidly metabolized via the portal vein , providing quick energy. It has slight choles-

* Correspondence to: Professor D. K. Bhattacharyya, Department of Chemical Technology, University of Calcutta, University Colleges of Science \& Technology, 92, A.P.C. Road, Kolkata 700009, INDIA E-mail: dkb_oiltech@rediffmail.com Accepted April 24, 2009 (recieved for review February 2, 2009)

Journal of Oleo Science ISSN 1345-8957 print / ISSN 1347-3352 online

http://www.jstage.jst.go.jp/browse/jos/ 


\section{S. Dasgupta and D.K. Bhattacharyya}

terol lowering capacity because it decreases the intestinal absorption of cholesterol and slows its synthesis from acetyl CoA in the liver. There is report that MCT decreases blood and liver cholesterol level ${ }^{6)}$. When medium chain capric acid is introduced in phospholipids, the properties developed may be helpful in reducing triglyceride, VLDLcholesterol in serum. Polyunsaturated fatty acid (PUFA) such as eicosapentaenoic acid (EPA, C20:5n-3) containing soyphospholipids has been reported to have nutritional benefits particularly in reducing TC, LDL - cholesterol, VLDL - cholesterol, TG and increasing the level of HDL cholesterol in serum of the rats ${ }^{7}$.

The dietary effect of medium chain saturated fatty acid (MCSFA) containing soyphospholipids has not been reported till date and one can expect interesting nutritional response particularly in regard to the lipid profile of serum of the MCSFA- rich soyphospholipids.

The present study aims to evaluate the dietary effect of MCSFA such as capric acid containing soyphospholipids on the lipid profile such as TC, LDL - cholesterol, HDL cholesterol, VLDL - cholesterol, TG of serum in growing rats compared to dietary soyphospholipids devoid of capric acid along with soybean oil as the dietary oil.

\section{EXPERIMENTAL}

\subsection{Materials}

\subsubsection{Soybean oil}

Soybean oil branded name Aadhaar, manufactured and packed by Acalmar Oils and Fats Limited, Hyderabad, India was used as a dietary oil.

\subsubsection{Soyphospholipids}

Soyphospholipids used in this study was supplied by V.P. Industries M.P. India.

2.1.3 Fatty acids

Capric acid (C10:0) was purchased from E. Merck (India) Ltd. (Bombay, India).

2.1.4 Chemicals and solvents

Except otherwise specified, all chemicals and solvents were purchased from S.D.Fine Chemicals (India) Ltd.

\subsection{Experimental procedures}

\subsubsection{Deoiling of soyphospholipids ${ }^{8)}$}

A crude sample of soyphospholipids was deoiled by repeated treatment with acetone (in $1: 7 \mathrm{w} / \mathrm{v}$ ratio ) at $4^{\circ} \mathrm{C}$ for $2 \mathrm{~h}$ followed by filtration to isolate the soyphospholipids in crystallised form. This treatment was repeated until the acetone layer was colourless. The acetone insoluble fraction was carefully dried to yield deoiled soyphospholipids at about $54 \%$.

2.2.2 Preparation of methyl esters for soyphospholipidsmonoester interchange reaction

Methyl ester of capric acid was prepared from a com- mercial sample. Fatty acid and dry methanol (1:5 molar ratio) was taken in a round bottomed flask and refluxed for $6 \mathrm{~h}$ with an air condenser and $\mathrm{CaCl}_{2}$ guard tube after adding 5\% concentrated sulphuric acid as a catalyst. After $6 \mathrm{~h}$ the excess alcohol was distilled off and methyl ester containing some alcohol, sulphuric acid and some fatty acid were taken in a separating funnel. Fatty acid, sulphuric acid and alcohol were washed out by $10 \%$ sodium bicarbonate solution and distilled water and the ester thus obtained was dried with anhydrous sodium sulphate. The purity and the composition of the ester was determined by gas liquid chromatography (GLC).

2.2.3 Soyphospholipids-monoester interchange reaction by lipase

Soyphospholipids and methyl ester of fatty acid in 1:5 molar ratio (to solubilise the soyphospholipids) were taken in a $50 \mathrm{~mL}$ round bottomed flask and stirred by a magnetic stirrer at $60 \pm 2^{\circ} \mathrm{C}$ for 10 days by using 15\% (by weight of the reactants) of Mucor miehei lipase (10\% w/w water content). The product was analyzed at definite time interval and finally after 10 days incubation the product mixture was filtered to remove the enzyme. Transesterified soyphospholipids were isolated by separation from the mixed methyl esters of fatty acid by extraction with acetone.

\subsection{Analysis of fat products}

GLC was employed for determination of fatty acid composition of the methyl esters of component fatty acids of soybean oil and soyphospholipids after their conversion into methyl esters by $\mathrm{BF}_{3}$ methanol ${ }^{9)}$.

\subsection{Preparation of dietary fat}

Blending of original soyphospholipids and capric acid containing soyphospholipids with soybean oil was done at the level of $5 \%$ and $10 \%$.

\subsection{Feeding Experiment}

\subsubsection{Experimental animals and diets}

The animal experiment was designed based on earlier reports ${ }^{10)}$. Male Albino rats (Charles Foster Strain) weighing an average of $60 \mathrm{~g}$ were housed individually in stainless steel cages with mesh floors in a room maintained under constant temperature $\left(20-25^{\circ} \mathrm{C}\right)$ and a $10 \mathrm{~h}$ light/14 h dark cycle (the experiment was done during winter season but all the experimental conditions were kept constant). Following 10 day adaptation during which the animals were maintained on a standard diet ${ }^{10)}$ and water ad libitum, rats were divided into five groups of 8 rats per group. Soybean oil and soybean oil blended with soyphospholipids at 5\% and 10\% levels were taken as control and the other two groups were kept as experimental (soybean oil blended with capric acid containing soyphospholipids at 5\% and $10 \%$ levels). The feeding experiment was carried out for 
four weeks. Food intake was measured daily while growth of the animals was monitored once a week.

Each group of rat fed different dietary oil while the other dietary components were same. Carbohydrate was supplied by corn starch (I.P. grade) which contributed 55\% of the diet $18 \%$ of the diet derived from casein, cellulose which contributed to $3 \%$ of the diet. $4 \%$ of the diet was derived from ash, which was supplied by mineral mixture, (composition of mineral mixture $\mathrm{No} .12$ (in g): $\mathrm{NaCl} 292.5$, $\mathrm{KH}_{2} \mathrm{PO}_{4}$ 816.6; $\mathrm{MgSO}_{4}$ 120.3; $\mathrm{CaCO}_{3}$ 800.8; $\mathrm{FeSO}_{4}, 7 \mathrm{H}_{2} \mathrm{O}$ 56.6; KI 1.66; $\mathrm{MnSO}_{4}$. $2 \mathrm{H}_{2} \mathrm{O}, 9.35 ; \mathrm{ZnCl}_{2}$ 0.5452; $\mathrm{CuSO}_{4}$. 5 $\mathrm{H}_{2} \mathrm{O}$, $\left.0.9988, \mathrm{CoCl}_{2} 6 \mathrm{H}_{2} \mathrm{O} 0.0476\right)^{11)}$. Total $20 \%$ fat and $0.01 \mathrm{~g}$ of vitamin capsule ( Vitamin A I.P.(Indian Pharmacopia) 10000 units, Thiamine mononitrate I.P. $5 \mathrm{mg}$, Riboflavin $5 \mathrm{mg}$, Pyridoxine hydrochloride $1.5 \mathrm{mg}$, Vitamin $\mathrm{B}_{12}$ I.P. $5 \mathrm{mg}$, Calcium pantothenate USP (United States Pharmacopia) 5 mg, Niacinamide I.P. 50 mg, Ascorbic acid I.P. 400 units, Cholecalciferol USP 15 units, Menadione I.P. $0.1 \mathrm{mg}$, Folic acid I.P. $1 \mathrm{mg}$, Vitamin E USP $0.1 \mathrm{mg}$ ) were also included in the diet. It has been reported phosphatidylcholine (PC) is better than full choline base diet in prompting growth of rats. $\mathrm{PC}$ is absorbed and converted better by the body and choline also possesses unpleasant side effects ${ }^{12}$. However earlier reports from the laboratory indicated satisfactory growth of rats without choline in the diet.

The Food Efficiency Ratio (FER) for each rat was calculated by the following equation.

$\mathrm{FER}=$ Body weight gain / Food consumed.

At the end of 4 weeks experimental period, $14 \mathrm{~h}$ fasted rats were subjected to a light anaesthesia using chloroform. The abdomen was opened, blood samples were collected from the hepatic vein and centrifuged at low speed $(3000 \mathrm{~g})$ to isolate the serum.

\subsection{Lipid analysis}

The lipid components such as $\mathrm{TC}^{13)}$, HDL-cholesterol ${ }^{14)}$, LDL-cholesterol ${ }^{15)}$, VLDL-cholesterol ${ }^{16)}$ and $\mathrm{TG}^{17)}$ of the serum were determined.

\subsection{Statistical analysis}

Data from the nutrition study were expressed as mean \pm standard error of mean (SEM). A oneway ANOVA was also used for statistical analysis between groups. The F ratio of one-way ANOVA is significant when $\mathrm{P}<0.05$. Tukey's multiple range method ${ }^{18)}$ was used for comparison. The statistical program was ORIGIN 7 (Origin Lab Corporation, One Roundhouse Plaza, Northampton, MA 01060 USA).

\section{RESULTS}

\subsection{Fatty acid composition}

The fatty acid composition of soybean oil, soyphospholipids and capric acid containing soyphospholipids are shown in Table 1.

\subsection{Growth rate}

Table 2 and 3 indicate the weight gain and food intake, FER and Figs. 1 and 2 indicate the growth pattern and the FER of rats fed soybean oil, soybean oil blended with soyphospholipids at 5\% and 10\% levels and soybean oil blended with capric acid containing soyphospholipids at $5 \%$ and $10 \%$ levels. These figures indicate that there is no significant change in growth response but FER of $3^{\text {rd }}$ and $4^{\text {th }}$ week is significantly different in experimental groups in comparison with the control groups.

Table 1 Fatty Acid Profile of Dietary Oils.

\begin{tabular}{|l|c|c|c|c|c|c|}
\hline \multirow{2}{*}{ Dietary Oils } & \multicolumn{5}{|c|}{ Fatty Acids (\% w/w) } \\
\cline { 2 - 7 } & $\begin{array}{l}\text { Capric } \\
\text { acid (10:0) }\end{array}$ & $\begin{array}{l}\text { Palmitic } \\
\text { acid (16:0) }\end{array}$ & $\begin{array}{l}\text { Stearic } \\
\text { acid (18:0) }\end{array}$ & $\begin{array}{l}\text { Oleic acid } \\
(18: 1)\end{array}$ & $\begin{array}{l}\text { Linoleic } \\
\text { acid (18:2) }\end{array}$ & $\begin{array}{l}\text { Linolenic } \\
\text { acid (18: } \\
3 n-3)\end{array}$ \\
\hline Soybean Oil (SBO) & - & 10.5 & 4.4 & 21.6 & 54.7 & 8.8 \\
\hline $\begin{array}{l}\text { Soyphospholipids } \\
\text { (SPL) }\end{array}$ & - & 25.7 & 2.9 & 14.7 & 52.5 & 4.2 \\
\hline $\begin{array}{l}\text { Medium Chain } \\
\text { Capric acid } \\
\text { Containing } \\
\text { Soyphospholipids } \\
\text { (C10-SPL) }\end{array}$ & 10.1 & 20.7 & 1.8 & 12.0 & 52.4 & 3.2 \\
\hline
\end{tabular}




\section{S. Dasgupta and D.K. Bhattacharyya}

Table 2 Mean Body Weight Gain of Rats fed Soybean Oil (SBO), SBO with Soyphospholipids (SPL) at $5 \%$ and $10 \%$ Levels and SBO with Capric Acid Containing Soyphospholipids (C10-SPL) at 5\% and 10\% Levels at the End of 4 Weeks.

\begin{tabular}{|lcccc|}
\hline \multirow{2}{*}{ Dietary Fat Groups } & \multicolumn{4}{c|}{ Average Weight Gain (gm / Week) } \\
& I & II & III & IV \\
\hline SBO & $7.00 \pm 0.86$ & $16.00 \pm 1.37$ & $22.00 \pm 2.58$ & $28.00 \pm 1.93$ \\
SBO + SPL at 5\% level & $7.67 \pm 1.41$ & $14.33 \pm 2.94$ & $26.33 \pm 4.14$ & $30.33 \pm 2.22$ \\
SBO + SPL at 10\% level & $9.33 \pm 0.67$ & $15.67 \pm 1.20$ & $27.00 \pm 1.53$ & $34.67 \pm 2.29$ \\
SBO + C10-SPL at 5\% level & $9.67 \pm 1.67^{\mathrm{a}}$ & $19.67 \pm 2.50^{\mathrm{a}}$ & $29.33 \pm 2.51^{\mathrm{a}}$ & $35.00 \pm 2.82^{\mathrm{a}}$ \\
SBO + C10-SPL at 10\% level & $7.33 \pm 1.23^{\mathrm{b}}$ & $17.67 \pm 2.85^{\mathrm{b}}$ & $29.33 \pm 3.33^{\mathrm{b}}$ & $33.33 \pm 2.46^{\mathrm{b}}$ \\
\hline
\end{tabular}

Values are mean \pm S.E.M, $n=6$

${ }^{a} \mathrm{SBO}+\mathrm{SPL}$ at $5 \%$ level vs SBO $+\mathrm{C} 10-\mathrm{SPL}$ at $5 \%$ level

${ }^{\mathrm{b}} \mathrm{SBO}+\mathrm{SPL}$ at $10 \%$ level Vs SBO $+\mathrm{C} 10-\mathrm{SPL}$ at $10 \%$ level

Table 3 Food Intake and Food Efficiency Ratio (FER) of Rats fed Soybean Oil (SBO), SBO with Soyphospholipids (SPL) at 5\% and 10\% Levels and SBO with Capric acid Containing Soyphospholipids (C10-SPL) at 5\% and 10\% Levels at the End of 4 Weeks.

\begin{tabular}{|lcrccc|}
\hline \multirow{2}{*}{ Dietary Fat Groups } & \multicolumn{5}{c}{ Food Intake } \\
& I & II & III & IV \\
\hline SBO & $67.33 \pm 0.67$ & $150.67 \pm 3.49$ & $218.33 \pm 3.48$ & $275.67 \pm 6.64$ \\
SBO + SPL at 5\% level & $49.67 \pm 1.58$ & $101.00 \pm 3.61$ & $150.67 \pm 3.56$ & $201.33 \pm 4.58$ \\
SBO + SPL at 10\% level & $53.00 \pm 1.77$ & $104.00 \pm 3.46$ & $159.33 \pm 4.02$ & $211.67 \pm 3.77$ \\
SBO + C10-SPL at 5\% level & $50.00 \pm 1.15^{\mathrm{a}}$ & $103.00 \pm 1.24^{\mathrm{a}}$ & $155.33 \pm 2.51^{\mathrm{a}}$ & $207.67 \pm 1.50^{\mathrm{a}}$ \\
SBO + C10-SPL at 10\% level & $49.67 \pm 1.74^{\mathrm{b}}$ & $104.67 \pm 2.62^{\mathrm{b}}$ & $156.33 \pm 3.74^{\mathrm{b}}$ & $209.33 \pm 5.02^{\mathrm{b}}$ \\
\hline Dietary Fat Groups & & \multicolumn{3}{c}{ FER } & \\
\hline SBO & $\mathbf{I}$ & II & III & IV \\
SBO + SPL at 5\% level & $0.10 \pm 0.01$ & $0.11 \pm 0.01$ & $0.10 \pm 0.01$ & $0.09 \pm 0.01$ \\
SBO + SPL at 10\% level & $0.18 \pm 0.02$ & $0.14 \pm 0.02$ & $0.17 \pm 0.02$ & $0.15 \pm 0.01$ \\
SBO + C10-SPL at 5\% level & $0.19 \pm 0.03^{\mathrm{a}}$ & $0.19 \pm 0.02^{\mathrm{a}}$ & $0.19 \pm 0.01^{\mathrm{a}}$ & $0.17 \pm 0.01^{\mathrm{a}}$ \\
SBO + C10-SPL at 10\% level & $0.15 \pm 0.02^{\mathrm{b}}$ & $0.17 \pm 0.02^{\mathrm{b}}$ & $0.18 \pm 0.02^{\mathrm{b}}$ & $0.16 \pm 0.01^{\mathrm{b}}$ \\
\hline
\end{tabular}

Values are mean \pm S.E.M, $n=6$

${ }^{\text {a }} \mathrm{SBO}+\mathrm{SPL}$ at $5 \%$ level vs SBO $+\mathrm{C} 10-\mathrm{SPL}$ at $5 \%$ level

${ }^{\mathrm{b}} \mathrm{SBO}+\mathrm{SPL}$ at $10 \%$ level Vs SBO $+\mathrm{C} 10$-SPL at $10 \%$ level

\subsection{Lipid profile}

Table 4 shows the plasma TC ,TG, HDL-cholesterol, LDL-cholesterol and VLDL-cholesterol level of rats raised on soybean oil, soybean oil containing by weight $5 \%$ or $10 \%$ soyphospholipids and soybean oil blended with capric acid containing soyphospholipids of $5 \%$ or $10 \%$ level by weight.
There is no significant change in the plasma lipid profile among the rats fed soybean oil and soybean oil blended with soyphospholipids at the level of 5\% and 10\%. A significant decrease in the content of TC and HDL-cholesterol among the rats fed soybean oil with capric acid containing soyphospholipids at the level of $5 \%$ has been observed as 


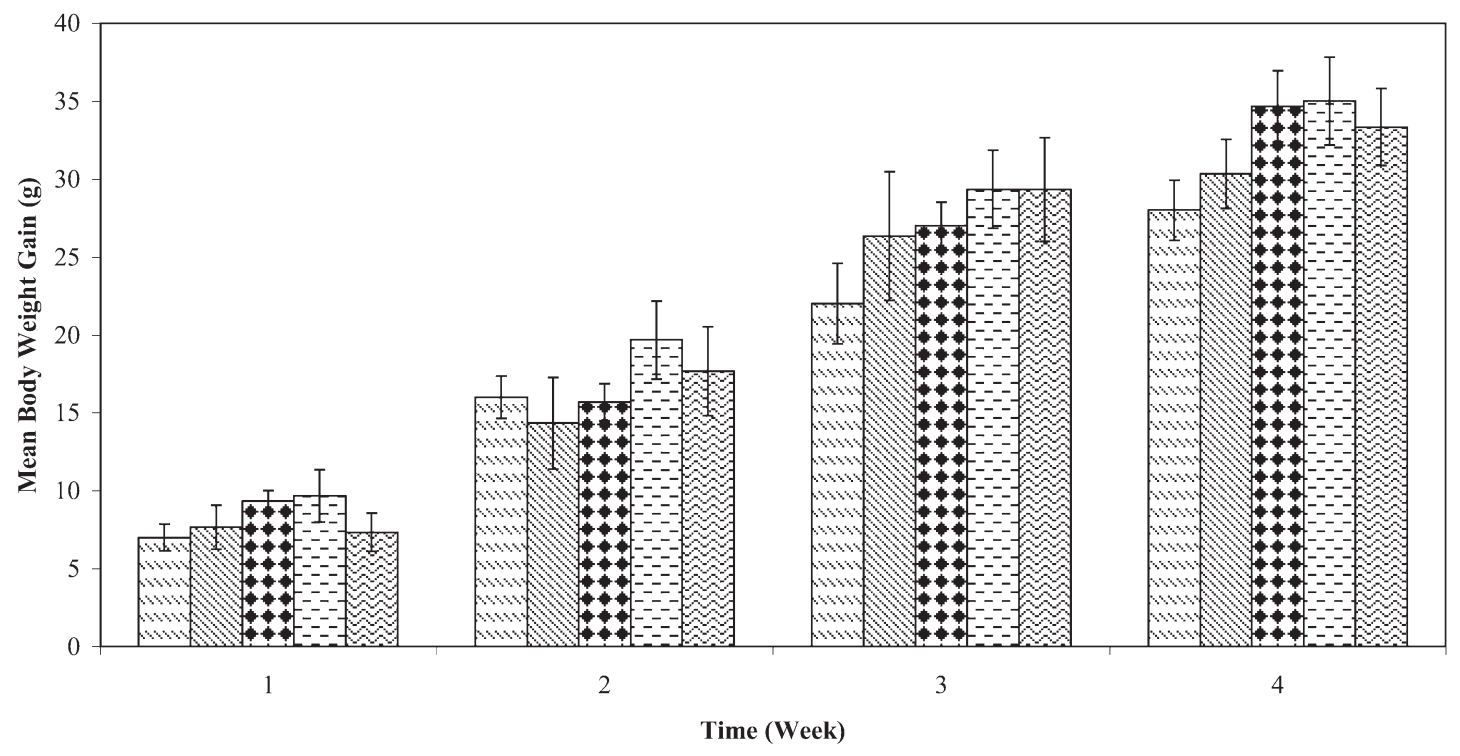

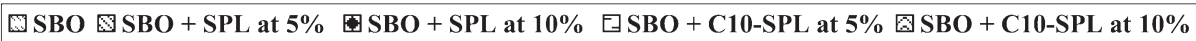

Fig. 1 Mean Body Weight Gain of the Rats Fed Soybean Oil (SBO), SBO Blended with Soyphospholipids (SPL) at the Level of $5 \%$ and $10 \%$ and SBO Blended with Capric Acid Containing Soyphospholipids (C10-SPL) at the Level of 5\% and $10 \%$.

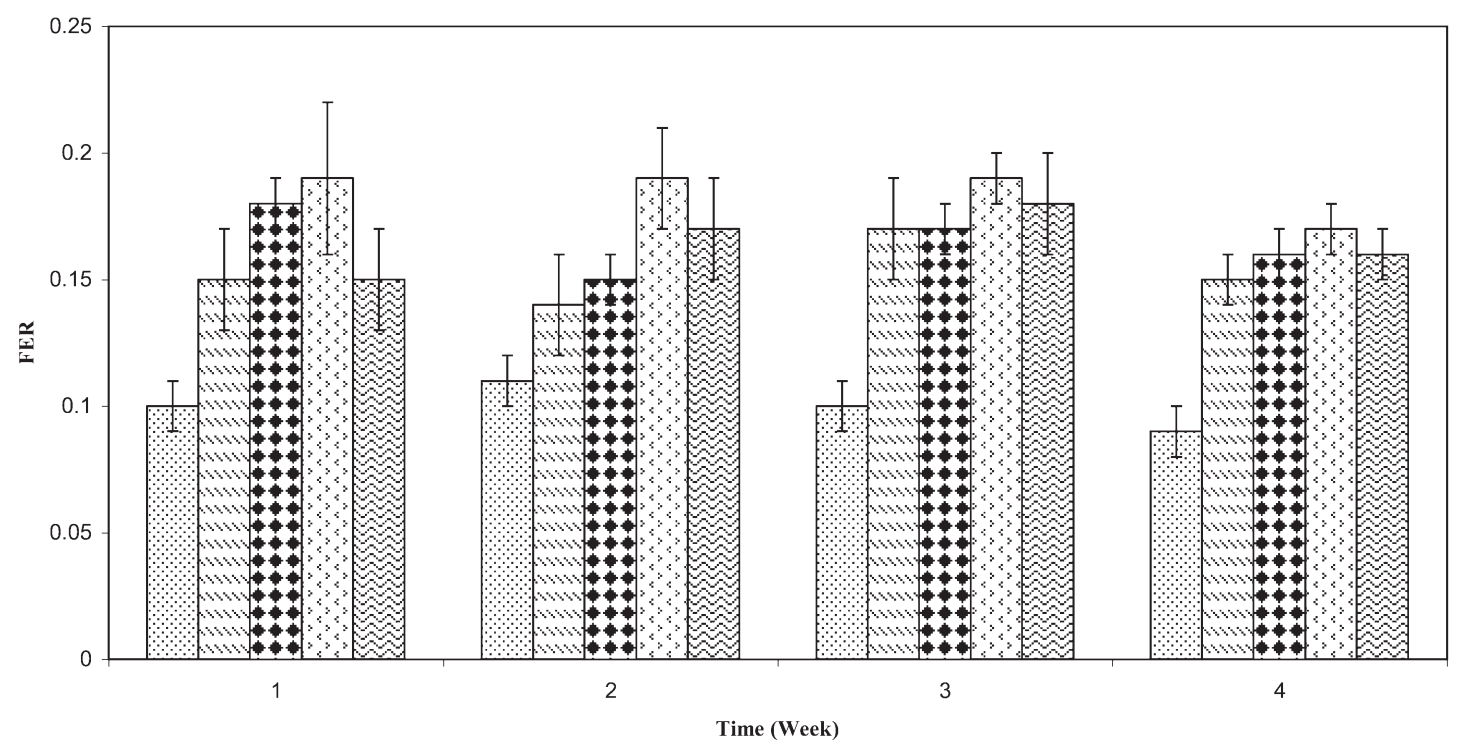

SBO $⿴$ SBO + SPL at 5\% 1 SBO + SPL at $10 \%$ SBO + C10-SPL at $5 \%$ - $\mathrm{SBO}+\mathrm{C} 10-\mathrm{SPL}$ at $10 \%$

Fig. 2 Food Efficiency Ratio (FER) of the Rats Fed Soybean Oil (SBO), SBO Blended with Soyphospholipids (SPL) at the Level of 5\% and 10\% and SBO Blended with Capric Acid Containing Soyphospholipids (C10-SPL) at the Level of 5\% and $10 \%$. 
Table 4 Lipid Profile of Serum of the Rats Fed Soybean Oil (SBO), SBO with Soyphospholipids (SPL) at 5\% and 10\% Levels and SBO with Capric Acid Containing Soyphospholipids (C10-SPL) at 5\% and 10\% Levels.

\begin{tabular}{|lccccc|}
\hline \multicolumn{1}{|c}{ Dietary Fat Groups } & $\begin{array}{c}\text { Total } \\
\text { Cholesterol } \\
(\mathbf{m g} / \mathbf{d l})\end{array}$ & $\begin{array}{c}\text { Triglyceride } \\
\mathbf{( m g / d l )}\end{array}$ & $\begin{array}{c}\text { HDL- } \\
\text { Cholesterol } \\
(\mathbf{m g} / \mathbf{d l})\end{array}$ & $\begin{array}{c}\text { VLDL- } \\
\text { Cholesterol } \\
(\mathbf{m g} / \mathbf{d l})\end{array}$ & $\begin{array}{c}\text { LDL- } \\
\text { Cholesterol } \\
(\mathbf{m g} / \mathbf{d l})\end{array}$ \\
\hline SBO & $52.74 \pm 2.06$ & $89.93 \pm 2.95$ & $27.87 \pm 2.44$ & $17.98 \pm 0.59$ & $8.54 \pm 1.09$ \\
SBO + SPL at 5\% level & $50.45 \pm 1.46$ & $78.41 \pm 6.91$ & $29.42 \pm 1.06$ & $15.68 \pm 1.38$ & $5.35 \pm 1.07$ \\
SBO + SPL at 10\% level & $53.27 \pm 0.92$ & $85.75 \pm 3.65$ & $26.70 \pm 0.88$ & $17.15 \pm 0.73$ & $9.42 \pm 1.89$ \\
SBO + C10-SPL at 5\% level & $42.37 \pm 1.86^{\mathrm{a}}$ & $72.12 \pm 1.65$ & $22.87 \pm 1.62^{\mathrm{a}}$ & $14.42 \pm 0.33$ & $5.75 \pm 0.80$ \\
SBO $+\mathbf{C 1 0 - S P L}$ at 10\% level & $44.06 \pm 2.65^{\mathrm{b}}$ & $64.41 \pm 2.35^{\mathrm{b}}$ & $25.75 \pm 2.46$ & $12.88 \pm 0.47^{\mathrm{b}}$ & $5.42 \pm 0.95$ \\
\hline
\end{tabular}

Values are mean \pm S.E.M, $n=6$ Significant $F$ ratio for total cholesterol ( $\mathrm{p}$ value $: 0.0001$ ), triglyceride ( $\mathrm{p}$ value $: 0.00079$ ), LDL-cholesterol ( $p$ value : 0.009), VLDL-cholesterol ( $p$ value : 0.00079).

${ }^{\text {a }} \mathrm{SBO}+\mathrm{SPL}$ at $5 \%$ level vs SBO $+\mathrm{C} 10-\mathrm{SPL}$ at $5 \%$ level

${ }^{\mathrm{b}} \mathrm{SBO}+\mathrm{SPL}$ at $10 \%$ level Vs SBO $+\mathrm{C} 10-\mathrm{SPL}$ at $10 \%$ level

compared with the rats fed soybean oil with the original soyphospholipids at $5 \%$ level. There is also significant decrease in TC, TG, VLDL-cholesterol among the rats fed soybean oil with capric acid containing soyphospholipids at the level of $10 \%$ when compared with the rats fed soybean oil with soyphospholipids at $10 \%$ level. There is overall significant change in TC, TG, VLDL- and LDL-cholesterol.

\section{DISCUSSION}

The present study was undertaken to compare the dietary effect between capric acid containing soyphospholipids and the original soyphospholipids without having capric acid along with soybean oil. The weight gain and FER were nearly identical between the two experimental rat groups. FER differs significantly at the $3^{\text {rd }}$ and $4^{\text {th }}$ week of study. However there was indication of significant differences in the lipid profile of serum between the two groups, namely, capric acid containing soyphospholipids and soyphospholipids without capric acid. There is no significant change in lipid profile of the rats fed soybean oil blended (mixed) with soyphospholipids at 5\% and 10\% levels when compared with the rats fed soybean oil alone but in the case of rats fed soyphospholipids containing capric acid along with the soybean oil a change in lipid profile was observed. In fact, there was significant decrease in TC and HDL-cholesterol among the rats fed soybean oil with soyphospholipids containing capric acid at 5\% level as compared with rats fed soybean oil with original soyphospholipids at the level of $5 \%$. There was significant decrease in the content of TC, TG, VLDL-cholesterol among the rats fed soybean oil and soyphospholipids containing capric acid at $10 \%$ level when compared with the rats fed soybean oil with soyphospholipids at the level of $10 \%$. A positive beneficial effect could be claimed when modified soyphospholipids is used. Soyphospholipids containing capric acid gives better result at 10\% level in respect of lipid profile.

When medium chain capric acid is introduced in soyphospholipids, the properties developed may be helpful in reducing TG and VLDL-cholesterol in serum. Phospholipid is reportedly hypocholesterolemic but this kind of effect is not however revealed with dietary phospholipids fed to rats in the present investigation. However when capric acid containing phospholipids is ingested to rats distinct beneficial effects in respect of lipid profile is observed.

The interfacial tension of soyphospholipids is 17.6 dynes/cm while that of the capric acid containing soyphospholipids is 13.8 dynes/cm when measured against water at $27^{\circ} \mathrm{C}$ using chloroform solution of $0.4 \%$ soyphospholipids ${ }^{19}$. The lowering of interfacial tension presumably promoted the transfer of cholesterol to bile to a greater extent thereby reducing the TC, TG, VLDL-cholesterol levels.

Modified phospholipid with capric acid might have influenced the cholesterol metabolism in the enterocyte, resulting in an increased excretion of cholesterol into the intestinal lumen and as a result decreasing cholesterol absorption in serum.

The modulation of serum lipid profiles thereby showing hypolipidemic effects may be attributed to the much greater extent of emulsification of lipid molecules including cholesterol incase of capric acid containing soyphospholipid as a dietary component.

The present work establishes the dietary effect of capric acid containing soyphospholipids and that the work points its edge over the soyphospholipids as a hypolipidemic lipid 
material.

\section{CONCLUSION}

Capric acid containing soyphospholipids have distinctly more hypocholesterolemic and hypotriacylglycerolidemic activity than that of the soyphospholipids when ingested at $10 \%$ level by weight of dietary soybean oil.

\section{ACKNOWLEDGEMENT}

The study was financially supported by University Grants Commission (Government of India).

\section{References}

1. Ziesel, S.H. Lecithins in AOCS monograph (Szuhaj, B.F.; List, G.R. ed.). III, Am. Oil Chem. Soc., Champaign, p.323 (1985).

2. Verheij, H.M. Fundamentals of Lipid Chemistry (Burton, R.M.; Guerra, F.C. ed.). BI Science Publication Division, Webster Groves, Mo., p.225 (1974).

3. Childs, M.T.; Bowlin, J.A.; Ogilvie, J.T.; Hazzard, W.R.; Albers, J.J. Atherosclerosis, 38, 217 (1981).

4. Rampone, A.J.; Machida, C.M. J. Lipid Res. 22, 744 (1981).

5. Ghosh, M.; Bhattacharyya, D.K. Soy lecithin-monoester interchange reaction by microbial lipase. J. Am. Oil Chem. Soc. 74, 761-763 (1997).

6. Bach, A.C.; Babayan, V.K. Medium chain triglycerides : An update. Am. J. Clinical Nutr. 36, 950-962 (1982).

7. Dasgupta, S.; Bhattacharyya, D.K. Dietary effect of eicosapentaenoic acid (EPA) containing soyphospholipid. J. Oleo Sci. 56, 563-568 (2007).

8. Harnas, C.; Perrin, J.L. Gram-scale preparative HPLC of phospholipids from soybean lecithins. J. Am. Oil Chem. Soc. 68, 804-808 (1991).

9. Metcalfe, L.D.; Schmitz, A.A. The rapid preparation of fatty acid esters for gas chromatographic analysis. Anal. Chem. 33, 363-364 (1961).

10. Ray, S.; Bhattacharyya, D.K. Comparative nutrition study of enzymatically and chemically interesterified palm oil products. J. Am. Oil. Chem. Soc. 72, 327-330 (1995).

11. Joanes, J.H.; Foster, C.A Salt mixture for use with basal diet either low or high in phosphorus. J. Nutr. 24, 245256 (1942).

12. Schneider, M. Phospholipids Proceedings World Conference on Emerging Technologies in the Fats and Oils Industry (Baldwin, A.R. ed.). Am. Oil Chem. Soc. 163 (1985).

13. Allain, C.C.; Poon, L.S.; Chan, C.S.G.; Richmond, W.; Fu, P.C. Enzymatic determination of total serum cholesterol. Clin. Chem. 20, 470-475 (1974).

14. Warnick, G.R.; Nguyen, T.; Albers, A. Comparison of improved methods for quantification of high-density lipoprotein. Clin. Chem. 31, 217-222 (1985).

15. Friedwald, W.T.; Levy, R.I.; Fredrickson, D.S. Estimation of the concentration of low density lipoprotein cholesterol in plasma without use of preparative ultracentrifuge. Clin. Chem. 18, 499-502 (1972).

16. Hatch, F.T.; Lees, R.S. Practical methods for plasma lipoprotein analysis. Adv. Lipid Res. 6, 1-68 (1968).

17. Bucolo, G; David, M. Quantitative determination of serum triglyceride by the use of enzymes. Clin. Chem. 19, 476-482 (1973).

18. Biometrica Tables for Statisticians (Pearson, S; Hartley, H.O. ed.). 1, Table 12, Cambridge University Press, Cambridge (1966).

19. Nandi, S. Studies on processing of some refinery byproducts for better utilisation in Ph.D. Thesis. University of Calcutta. p.169 (2005). 